\title{
"O LUGAR DE MULHER É NO LAR. O TRABALHO FORA DE CASA MASCULINIZA": UMA ANÁLISE DISCURSIVA DO LAR FEMININO NO JORNAL DAS MOÇAS NA DÉCADA DE 50
}

\author{
Kyrlian de Araújo Lima Pedreira Lapaㅜ; Palmira Palmira Virgínia Bahia Heine \\ Alvarez ${ }^{2}$ \\ 1. Bolsista PROBIC/UEFS, Graduando em Licenciatura em Letras e Inglês, Universidade Estadual de Feira de Santana, \\ email: kyrlianlima@gmail.com \\ 2. Orientadora, Departamento de Letras e Artes, Universidade Estadual de Feira de Santana, email: pavibheinve@gmail.com
}

PALAVRAS CHAVE: mulher, lar, discurso.

\section{INTRODUÇÃO}

A pesquisa realizada investiga a construção discursiva da mulher associada ao lar na revista Jornal das Moças na década de 1950. Através do aparato teórico da Análise do Discurso de Linha Francesa (ADLF), que relaciona sujeito, história, ideologia e língua, analiso como se constrói a imagem da mulher submissa ao homem, relegada ao lar e responsável pela moral e manutenção dos bons costume e boa aparência social da família.

A ADLF, surgida na década de 60, redireciona a concepção de discurso, considerando-o a materialização da ideologia. Michel Pêcheux (1969) situa os estudos do discurso entre três áreas do conhecimento: o materialismo histórico, como teoria das formações sociais e de suas transformações, compreendida aí a teoria das ideologias; a linguística como teoria dos mecanismos sintáticos e dos processos de enunciação ao mesmo tempo; a teoria do discurso, como teoria da determinação histórica dos processos semânticos. Tudo isso aliado ao princípio de inconsciente trazido da psicanálise e que constitui os sujeitos.

Para Pêcheux, o discurso é "efeito de sentido entre os pontos A e B", sendo A e B compreendidos como a projeção do lugar ocupado pelos sujeitos no discurso. O discurso é, assim, a materialização da ideologia através da linguagem. Dessa forma, é necessário compreender que o indivíduo é interpelado em sujeito pela ideologia. Assim, inconsciente e ideologia funcionam para produzir determinado discurso, a partir de uma posição dada, em uma conjuntura dada, isto é, numa certa relação de lugares no interior de um aparelho ideológico, e inscrita numa relação de classes.

À luz da ADLF, analiso o periódico Jornal das Moças, que foi uma revista de circulação no Brasil entre 1914 e 1968. Destinada ao público feminino, a revista abordava temas considerados "de mulher" como moda, cozinha, decoração do lar, afazeres domésticos, casamento, costura, vida das celebridades, educação familiar entre outros assuntos.

Utilizo também nas análises a contribuição de Louis Althusser e sua concepção de Aparelhos Ideológicos de Estado, essencial para compreender o funcionamento da ideologia e a difusão das ideias dominantes. Para o autor, cabe aos Aparelhos Ideológicos a difusão da ideologia dominante que funciona de modo a homogeneizar os sujeitos.

Dito isto, não busco desvendar a materialidade discursiva da revista, no sentido de descobrir o que está por trás do discurso, ou o que este "quer dizer", mas procuro evidenciar como se constrói a imagem discursiva da mulher no lar no corpus utilizado para análise.

\section{MATERIAIS E MÉTODOS}


Para a realização da pesquisa, forma selecionadas dez exemplares da revista que circularam na década de 50 e que trazem discursos relacionados à mulher e ao lar. Após a seleção dos exemplares, foram feitos recortes que foram analisados à luz do aparato teórico da ADLF. Os exemplares utilizados foram acessados através da plataforma digital Biblioteca Nacional Digital.

A ADLF não pressupões uma análise quantitativa, mas se preocupa de trazer à tona os efeitos de sentido materializados na linguagem (verbal, textual, imagética, etc.), a partir da qual o analista realiza faz sua investigação. Assim, saindo da superficialidade da língua, busco analisar como se dá o funcionamento da ideologia e do interdiscurso na construção dos sentidos sobre a mulher.

\section{RESULTADOS E DISCUSSÃO}

A revista, considerada aqui como um Aparelho Ideológico de Estado, forma e é formada pelo conjunto das ideias dominantes sobre o feminino, ela naturaliza os fenômenos sociais que acompanham a construção histórica da submissão da mulher ao homem, de modo a reforçar os estereótipos do ser homem e ser mulher, com papéis, posições e comportamentos determinados socialmente. A revista, portanto, se relaciona de forma dialética com a construção e reprodução da ideologia dominante no que se refere a imagem da mulher.

Essa noção fica clara quando analisamos um recorte da revista Jornal das Moças da década de 50:

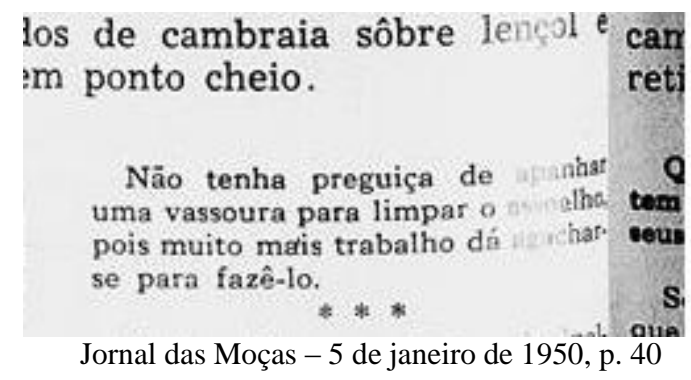

"Não tenha preguiça de apanhar uma vassoura para limpar o assoalho, pois muito mais trabalho dá agachar-se para fazê-lo." Este recorte - retirado do caderno Jornal da Mulher, que era destinado a mulheres, e não moças, ou seja, moças que haviam se casado e, portanto, teriam se tornado mulheres, e continha dicas de trato do lar, cozinha, educação dos filhos e questões matrimoniais - traz uma orientação às mulheres, ao trazê-la, já naturaliza uma atribuição "essencialmente" feminina, o cuidado do lar. É apresentado um problema, o assoalho sujo, caso a mulher tenha preguiça de pegar a vassoura para limpá-lo, ele provavelmente ficará mais sujo, já que seria obrigação exclusiva da mulher executar a tarefa e nenhuma outra pessoa poderia assumir essa responsabilidade, então, seria necessário agachar-se para realizar a tarefa, pois o assoalho estará mais sujo. A revista, neste recorte, naturaliza o que é ser mulher e suas funções, apresentando um afazer doméstico como exclusivamente de obrigação da mulher, e não do homem.

A ideologia, materializada no discurso, atribui à mulher a obrigação do trato do lar, negando a construção sócio-histórica dessa posição e partindo do pressuposto de que a realização das tarefas domésticas é, naturalmente, feminina. Os sentidos criados remetem aos já ditos sobre a mulher que é prendada, que sabe fazer tudo em casa, que nasceu para ser dona de casa, como se esses sentidos fossem gerados a partir de uma suposta essência feminina e não construtos sociais. 
Este é apenas um exemplo para ilustrar como a ideologia dominante se manifesta na revista e naturaliza os sentidos sobre o feminino de modo a atribuir à mulher uma posição submissa e coadjuvante na sociedade.

\section{CONSIDERAÇÕES FINAIS}

A análise dos dados, contexto histórico e recortes da revista demonstra que o periódico Jornal das Moças reproduz as ideias dominantes sobre o que é ser mulher, de maneira que a revista é interpelada e difunde esses sentidos ao mesmo tempo. A construção da imagem discursiva feminina se dá através da ideologia dominante que determina o que é ser mulher e as condições para a realização adequada da feminilidade. Deste modo, para ser mulher, na perspectiva da revista, é necessário ser mãe, dona de casa, submissa ao marido e aos homens em geral e prezar pela educação dos filhos.

O Jornal das Moças cria uma série de mecanismos de persuasão para apresentar suas regras como verdades universais, apelando para a imagem de "mulher elegante", utilizada diversas vezes no periódico como fator de convencimento. Apresenta suas regras como leis e consequências sociais graves àquelas que se recusarem a segui-las. Naturalizando o corpo, o comportamento, as atribuições e o que é ser mulher, a revista atesta a submissão feminina, fazendo-a parecer "normal", contribuindo para a manutenção deste estado de coisas e para a homogeneização dos sujeitos que impede outras formas de realização do ser.

Considerando a revista Jornal das Moças como um veículo midiático dentro dos Aparelhos Ideológicos do Estado, o discurso da revista é moldado e molda a sociedade no sentido de manter e legitimar a superexploração da mulher, essencial à reprodução da vida social e manutenção da ordem necessárias ao modo de produção capitalista. Exploração e legitimação que alcançam os dias atuais, o que faz deste trabalho um instrumento importante de compreensão do histórico sistema de dominação da mulher, que é estrutural e estruturante das relações sociais na sociedade de classes no contexto do patriarcal capitalismo.

\section{REFERÊNCIAS}

ALTHUSSER, Louis. Ideologia e Aparelhos Ideológicos do Estado. Lisboa: Presença, 1974.

BASSANEZI, Carla. Mulheres dos Anos Dourados. São Paulo: Contexto, 2014.

BLAY, Eva Alterman. Trabalho Domesticado: A Mulher na Indústria Paulista. São Paulo: Ática, 1978. In: CISNE, Mirla. Gênero, Divisão sexual do trabalho e Serviço Social. São Paulo: Outras Expressões, 2012.

Biblioteca Nacional Digital Brasil. Jornal das Moças. Disponível em: <http://memoria.bn.br/DocReader/docreader.aspx?bib=111031_05\&pasta=ano\%20195\&p esq=>. Acesso em: 10 de abril de 2017.

CISNE, Mirla. Gênero, Divisão sexual do trabalho e Serviço Social. São Paulo: Outras Expressões, 2012.

ORLANDI, Eni Puccinelli. Análise de Discurso: princípios \& procedimentos. Campinas: Pontes, 2009.

PÊCHEUX. Michel; FUCHS, Catherine. A propósito da análise automática do discurso: atualizações e perspectivas. In: GADET; HAK (Org.). Por uma análise automática do discurso. Campinas, SP: Ed. da Unicamp, 1997, p. 163 -252. 